\title{
Lukasiewicz and the Several Senses of Possibility
}

Trinity College Dublin, Ireland.

The most famous achievement of Jan Lukasiewicz (1878-1956) was to give the first rigorous formulation of many-valued logic. In this paper I discuss his motivations for this, which were philosophical, and the legacy of his work.

\section{Brief Life and Works}

Jan Łukasiewicz (1878-1956, Figure 1) was trained as a philosopher but made himself an expert in mathematical logic. Through his activities as a teacher in Lvov University before the First World War and even more as a professor in Warsaw University from 1920 to 1939 , he was a prime mover in establishing mathematical logic as a specialism in interwar Poland, to such an extent that Warsaw for some years became the foremost centre in the world for that discipline. He is celebrated, along with his teacher Kazimierz Twardowski, his colleague and contemporary Stanisław Leśniewski, and his student Alfred Tarski, in one of Adam Myjak's statues in the entrance hall of Warsaw University Library.

Łukasiewicz's life and career as an academic, scholar and public figure were severely disrupted by two world wars. He was born in Austrian-administered Lvov where he attended school and university, coming under the influence of the prime mover of Polish philosophy, Kazimierz Twardowski. Before 1914 he became Privatdozent and later Associate Professor. During the war he was recruited to the newly reopened Warsaw University, which he left in 1918 to work in government, serving under Paderewski as Minister for Education. Reappointed in 1920, he worked in Warsaw University as professor and was twice elected as rector. He continued to teach and take an active part in Polish and European academic affairs until the Nazi invasion, losing his possessions when the flat he shared with his wife was bombed. He then worked in the city archives and taught in the underground university until he and his wife left in 1944, attempting to reach Switzerland but becoming stuck in Germany, where they both remained until war's end. Refusing to return to Poland, in 1946 he was offered a position in Ireland at the Royal Irish Academy in Dublin, where he gave lectures until 1953. He died in Dublin in 1956. Very much at the centre 


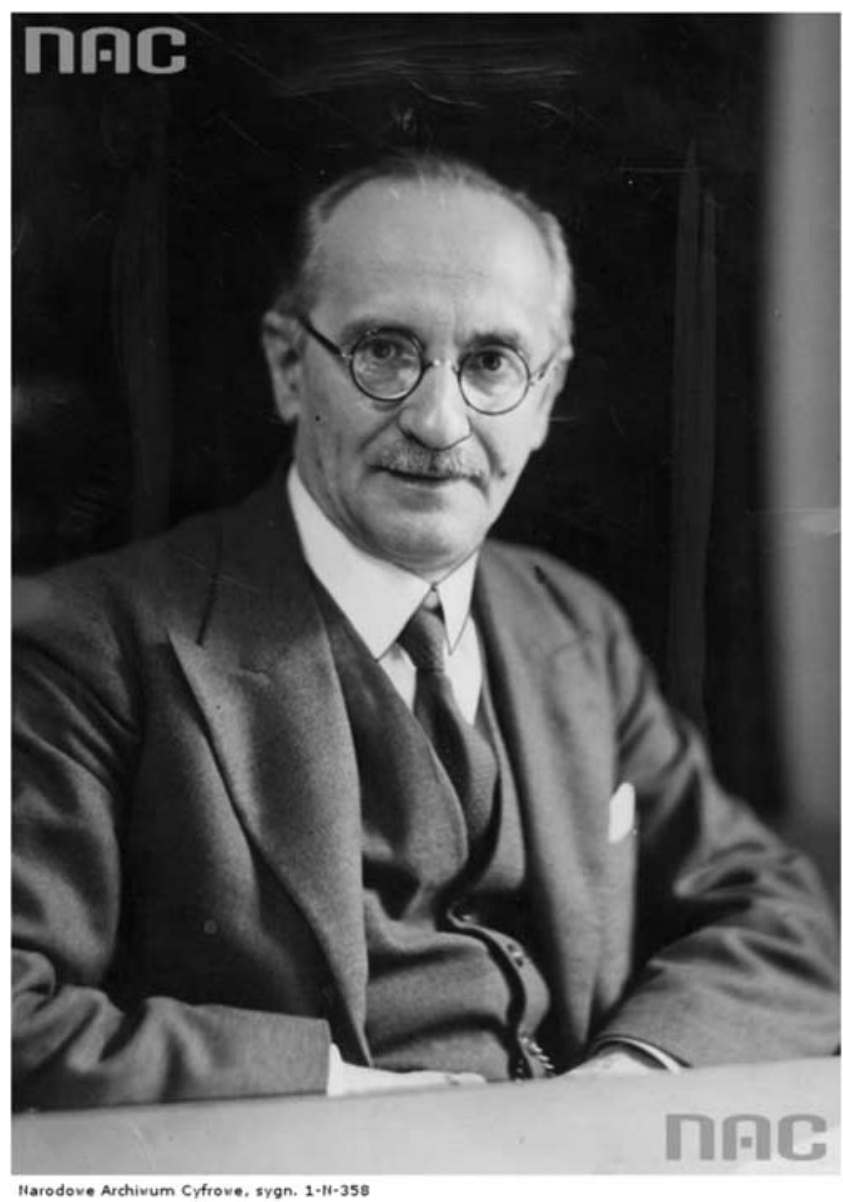

Figure 1. Jan Łukasiewicz, 1935.

of developments in mathematical logic between the wars, he was more isolated in

Ireland, which had no logical tradition. He married his wife Regina in 1929: they had 40 no children.

Lukasiewicz wrote three monographs and around 40 normal length papers, togechronological order, a critical analysis of Aristotle on the principle of contradiction (in Polish, 1910), a logical treatment of the foundations of probability (in German, 1913), and a reconstruction and appraisal of Aristotle's syllogistic using the methods of modern logic (in English, 1951, 2nd edition 1957). In addition, an authorized transcription of his University of Warsaw lecture notes on the elements of mathematical logic was published in 1929 (reissued in 1958, published in English translation 1963). The papers cover a variety of subjects including the methodology of science and the history of logic, but they are chiefly concerned with mathematical logic, with special attention being paid to various calculi of propositions, both classical 
Table 1. Łukasiewicz's notation.

\begin{tabular}{llll}
\hline \hline Name & Reading & Standard & Lukasiewicz \\
\hline Negation & It is not the case that $p$ & $\sim(p)$ & $N p$ \\
Conjunction & $p$ and $q$ & $(p \wedge q)$ & $K p q$ \\
Disjunction & $p$ or $q$ & $(p \vee q)$ & $A p q$ \\
Implication & If $p$ then $q$ & $(p \rightarrow q)$ & $C p q$ \\
Equivalence & $p$ if and only if $q$ & $(p \leftrightarrow q)$ & $E p q$ \\
Necessity & Necessarily $p$ & $\square(p)$ & $L p$ \\
Possibility & Possibly $p$ & $\diamond(p)$ & $M p$ \\
\hline \hline
\end{tabular}

(two-valued) and, Łukasiewicz's own creation, many-valued calculi. It is the last on which we concentrate here, as it is his most eminent achievement. His work on the history of logic however, notably on Aristotle but also on Stoic and medieval propositional logic, revolutionized that subject, taking it away from philology and towards logic as now understood and practised.

Lukasiewicz confessed to finding writing difficult, which is surprising, considering that his prose style is by common consent exceptionally clear and elegant. No doubt the technicality of many of his writings slowed him down, but he was able to present ideas in an extremely attractive way, as evidenced by those 1929 lecture notes. It is doubtless due in part to his ability to both inform and inspire students that so many exceptionally able minds were recruited to the cause of logic in interwar Warsaw.

One presentational innovation of his that achieved wide renown was his invention of bracketless notation for logical formulas, now known as Polish notation. In standard logic, operators on two sentences are written between the sentences, but this requires brackets to avoid ambiguity. Lukasiewicz's notation does not require this because operators are written before their operands. While not in itself a logical advance, it helped to facilitate dealing with complex formulas, especially at a time when handwriting had been displaced by typewriters but computers and Unicode were still in the future. Sadly this notation is now hardly used. Since we shall go against the trend here and use Lukasiewicz's notation, a set of equivalents is given in Table 1.

The table as such does not make clear the economy and transparency of Lukasiewicz's notation but this becomes more apparent if we compare his and the standard formulas for the sentence that we can render in logicians' semi-English as:

$p$ implies $r$ and $q$ implies $r$ and $p$ implies $s$ and $q$ implies $s$

if and only if $p$ or $q$ implies $r$ and $s$

Standard : $\quad((((p \rightarrow r) \wedge(q \rightarrow r)) \wedge((p \rightarrow s) \wedge(q \rightarrow s))) \leftrightarrow((p \vee q) \rightarrow(r \wedge s)))$

\section{Łukasiewicz: $\quad$ EKKCpqCqrKCpsCqsCApqKrs}

Not only is Lukasiewicz's version much shorter (23 symbols against 45), but it obviates the need for special conventions about suppressing brackets when these become oppressive, and every symbol is a meaningful contributor to the formula. 


\section{Preparing the Ground}

In the years before the First World War, Lukasiewicz worked mainly on the methodology of science. One aspect of this was the theory of probability. One of his two monographs published before the war was Logical Foundations of Probability Theory, written and published in German, after a visit in 1908-1909 to Graz and the school of philosophy there led by Alexius Meinong. It cleverly combines ideas from several sources: the ideas of truth-value (from Frege), indefinite propositions (from Russell) and variable components of propositions (from Bolzano). An indefinite proposition (one containing a variable) is said to be true if it yields a true proposition for all values of its variables, it is false if it yields a false judgement for all values, and is neither true nor false if it yields true judgements for some values and false judgements for others. The ratio of true values to all values is then called by Lukasiewicz the truth-value of the indefinite proposition. For true indefinites it is 1 , for false indefinites it is 0 , and for others it is a rational number between 0 and 1 (rational because only finite domains are considered).

On this basis, Łukasiewicz develops a calculus of truth-values in which he can deal with logically complex propositions, conditional probability, probabilistic independence, and derive Bayes' Theorem. The calculus of truth-values is used as a logical theory of probability, assisting us in our dealings with definite reality: Łukasiewicz denies that there can be a theory either of objective or of subjective probability as such. Two ideas from this short but remarkable work are worth emphasizing because they resonate with later ones of Łukasiewicz. First, there is the idea of a proposition (in this case an indefinite proposition) being neither true nor false; second, and connected with this, of such a proposition having a numerical truth-value properly between 0 (false) and 1 (true).

The other monograph Łukasiewicz published before the First World War, in 1910, was On the Principle of Contradiction in Aristotle. It marked a crucial turning point in the development of the Lvov-Warsaw school. For Lukasiewicz, it represented his first sustained questioning of the assumptions of traditional Aristotelian logic. The project of the monograph is a critical investigation of the legitimacy of the Principle of Contradiction (PC) as variously formulated by Aristotle. Łukasiewicz distinguishes three different, non-equivalent versions of PC in Aristotle: an ontological version, a logical version, and a psychological version. He criticises Aristotle for on the one hand claiming PC cannot be proved, and on the other hand attempting an indirect or pragmatic 'proof'. Łukasiewicz claims that PC's status is less secure than some other logical propositions, and that its function is principally to serve as a pragmatic norm. Nevertheless, in an Appendix to the book he gives a formal derivation of one version of PC from other assumptions. This shows that PC is, as it were, just one logical theorem among others, a statement that would raise few eyebrows today but was radical in its day. Among the assumptions used in the derivation is a version of the Principle of Bivalence, that every proposition is either true or false and none is both, so the derivation of PC is not after all such a surprise.

Łukasiewicz described himself later as attempting in the monograph to devise a 'non-Aristotelian logic' but admits that he did not succeed, principally because 
at this stage he was not prepared to reject the Principle of Bivalence. While not in itself a success, the book shows Lukasiewicz on the threshold of his later logical breakthroughs, and it promoted heated discussion in Lvov: Kotarbiński wrote in defence of Aristotle's idea, discussed by Łukasiewicz, that a statement about future contingent events may lack a truth-value before the event and only gain one afterwards, while Leśniewski wrote in opposition to this and brought Kotarbiński round to his own view (which agreed with earlier views of Twardowski and later ones of Tarski) that truth is timeless, or as Leśniewski expressed it, both eternal and sempiternal. Lukasiewicz was soon to side with the earlier Kotarbiński, and in so doing to make his most famous discovery, that of many-valued logic.

\section{Possibility, Indeterminism, and the Third Truth-value}

Łukasiewicz's most celebrated achievement was his development of many-valued logics. This revolutionary development came in the context of discussing logical modality, especially possibility. His approach is quite different from that of modern logic, where modal logic is an extension of classical bivalent logic, and many-valued logic is principally used in connection with the logical treatment of vagueness. Here is how Łukasiewicz arrived at the idea. If $p$ is any proposition, let $L p$ say that it is necessary that $p$, and $M p$ that it is possible that $p$. Everyone accepts the implications $C L p p$, that if necessarily $p$ then $p$, and $C p M p$, that if $p$, then possibly $p$ (see the $C$ notation for implication, 'if ... then ...' in the table above, and its truth-table given below). Lukasiewicz supposes one accepts also the converse implications $C p L p$ and $C M p p$, as one would from a deterministic point of view. That gives the equivalences $E p L p$ and EpMp, which collapse modal distinctions, since it means that any proposition $p$ is equivalent both to necessarily $p$ and to possibly $p$, so those modal operators have no effect. Now add in the idea that possibility is two-sided: if something is possible, then so is its negation: $E M p M N p$. From these it immediately follows that $E p N p$, and this is paradoxical in two-valued logic. The way out, as Łukasiewicz portrays it, is to 'uncollapse' the modal distinctions, not by rejecting any of the principles above but by finding a case where EpNp is true. Let us suppose there is a proposition $p$ which is neither true not false, but possible: $M p$. This can be accommodated if in addition to the usual two truth-values true (1) and false (0), we allow a third value, possible, which we write ' $1 / 2$ '. Then when $p$ is neither true nor false, it is possible, and so is its negation $N p$, for if $N p$ were true, $p$ would be false, and vice versa, and we are assuming $p$ is neither. Given that Epq is true when $p$ and $q$ have the same truth-value, then when $p$ is possible (we write ' $\mid p$ |' for the truth-value of $p$, so that $|p|=1 / 2)$ we have $|E p N p|=\left|E^{1 / 2} 1 / 2\right|=1$. short paper is based on a talk given on 5 June 1920 in Lvov. Two weeks later he gave a 
These in effect determine the truth-table for implication as:

\section{$q$}

\begin{tabular}{ll|lll}
$C p q$ & 1 & $\frac{1}{2}$ & 0 \\
\hline 1 & 1 & $\frac{1}{2}$ & 0 \\
$\frac{1}{2}$ & 1 & 1 & $\frac{1}{2}$ \\
0 & 1 & 1 & 1 \\
\hline
\end{tabular}

and together with fairly standard definitions of negation, conjunction, disjunction and equivalence determine truth-tables for the other usual connectives. Łukasiewicz proudly declares 'that three-valued logic has, above all, theoretical significance as the first attempt to create a non-Aristotelian logic.'

Lukasiewicz's motivation for replacing the old bivalent logic with the new trivalent coercion that restricts man's free creative activity.' The logical form of this coercion, in Łukasiewicz's view, was Aristotelian logic, which restricted propositions to true or false. His own weapon in this war was three-valued logic. He returned to the subject of determinism for his 1922 inaugural lecture as Rector of the University of Warsaw, published only posthumously in 1961 as 'On Determinism'. Distinguishing logical from causal determinism, Lukasiewicz claims that if a prediction of a future contingent event such as an action is true at the time the prediction is made, the event must occur, so the only way to rescue the agent's freedom of action is to deny that the prediction is true, and assign it instead the third truth-value of possibility.

\section{More than Three Values}

Once the spell of bivalence was broken, a natural next step was to consider logic with more than three values. In 1922 Lukasiewicz indicated how to give truth-tables for the standard connectives in systems with finitely or infinitely many truth values, according to the following principles, where the truth-values are numbers in the interval $[0,1]$ :

$$
\begin{array}{ll}
|C p q|=1 & \text { for }|p| \leq|q| \\
|C p q|=1-p+q & \text { for }|p|>|q| \\
|N p|=1-|p| &
\end{array}
$$

In proposing logics with infinitely many values, Lukasiewicz was thus the inventor of what four decades later came to be called 'fuzzy logic', which is a logic allowing for degrees of truth and is usually employed for dealing with inferences involving 
in degrees of the possible and consequently arrives at the three-valued system; or one assumes the opposite, in which case it would be most natural to suppose, as in the theory of probabilities, that there are infinitely many degrees of possibility, which leads to the infinite-valued propositional calculus. I believe that the latter system is preferable to all others. (Selected Writings, 173)

5. Second Thoughts on Modality: System $\mathbf{L}$

From 1917 Łukasiewicz had been happy with his three-valued logic as formulating adequate notions of modality, with the noted preference for the infinite-valued system as optimally precise. At some time, probably around 1951-52, when he was working on Aristotle's modal logic, Łukasiewicz changed his mind. There are a number of reasons behind the change of mind but the easiest to identify is Lukasiewicz's concern that in the three-valued logic there are theorems of the form Necessarily A, for example Necessarily, if $p$ then $p$. Why should this be a concern, given that most 'standard' modal logics recognize the principle that if $A$ is a theorem, so is Necessarily $A$ ? Łukasiewicz wrote:

I think [...] that true propositions are simply true without being necessary, and false propositions are simply false without being impossible. ( Selected Writings, 377)

Adding in a paper written around the same time,

it is commonly held that apodeictic propositions have a higher dignity and are more reliable than corresponding assertoric ones. This consequence is for me by no means evident. (Selected Writings, 395)

Since Necessarily if $p$ then $p$ was a theorem of all the systems of many-valued logic to date, Lukasiewicz needed to come up with something new. This he did in his 1953 paper 'A System of Modal Logic', developing a four-valued system $\_$with two distinct intermediate values representing possibility.

The ideas are presented there with Łukasiewicz's accustomed economy and elesystems. It is unlike his own systems in that it is an extension of classical bivalent logic and includes all bivalent tautologies. And several features make it very unlike standard modal systems. One is the complete lack of any truths, let alone theorems, of the 'higher dignity'. Other strange consequences are that all possible propositions are 'compossible', i.e. can be true together, that propositions which are equivalent are both possible if one is, and that if a proposition and its negation are both possible, then anything is possible. Łukasiewicz was aware of many of these odd consequences, but continued to uphold his system as the best available. Despite a number of attempts to make sense of the system, it has generally been concluded that because of these oddities it is not really a system of modal logic. The main reason for this is Lukasiewicz's adherence to the principle of extensionality (truth-functionality, according to which the truth-value of any compound proposition is a function solely 
for modal operators, and it was this adherence that forced his account of modality to go multivalent in the first place in 1917, and to remain so in 1953 despite the change in his preferred system. But whereas the three-valued system is clearly and neatly connected with the infinite-valued one, by simply equating all values other than 0 or 1 as the third value, the new four-valued system is not, and Łukasiewicz did not go on to explore their connection.

During his final years in Ireland Łukasiewicz's main project was his monograph on Aristotle's syllogistic. The first edition of this, published in 1951, dealt only with the categorical syllogistic and follows lines laid down in his pre-war Warsaw logic lectures. For the second edition, completed in 1955, less than a year before his death, Łukasiewicz added three chapters on the modal syllogistic, employing the modal logic $\_$that he had developed in the meantime. This second edition appeared posthumously in 1957.

\section{An Abiding Philosophical Motivation}

In addition to the generally scientific attitude to philosophizing that he inherited from Twardowski, there is one identifiable source of some other of Lukasiewicz's philosophical stances regarding logic, or if not a source, at least a point of convergent convictions. One is the rejection of a 'supertruth' above ordinary truth, which we

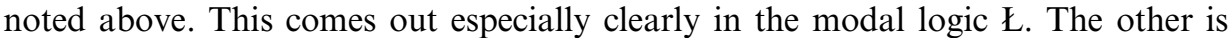
his liking for degrees of possibility intermediate between truth (1) and falsity (0), by contrast with the non-quantitative third case of possibility (or in $\_$the twin third cases). An exactly similar distinction between two kinds of possibility, 'unincreasable', without degrees, and 'increasable', with infinite degrees, can be found in Meinong's massive 1915 treatise Über Möglichkeit und Wahrscheinlichkeit, on which he had been working when Łukasiewicz visited Graz.

Meinong employed the many values of increasable possibility to give an account of probability. While Łukasiewicz's procedure in his 1913 monograph was based on a different idea, he continued to be pulled towards the idea that infinite-valued logic might be able to shed light on probability. At the very latest, by 1935, with the publication of a short article on probability and many-valued logic by Tarski, he knew that the most straightforward approach, that of identifying probabilities with truth-values between 0 and 1, would not work, but despite this, as late as 1955 Lukasiewicz could still muse on his (unrequited) desire to link his infinite-valued logic with probability theory.

\section{Legacy}

There are several aspects to Lukasiewicz's logical and scientific legacy. One of course is the interest and richness of the logical systems he invented. They have led to much fruitful mathematics and logic, in particular in regard to their algebraic semantics. More generally, he had a very positive effect on the high standards of rigour in logic, in Warsaw as elsewhere. Another and even more clearly attributable legacy is his 
almost universally pervasive influence on the way in which the history of logic is pursued. Nearly every writer on the history of logic, of no matter what period, now approaches the subject 'from the standpoint of modern formal logic'. That does not mean that modern writers are cavalier about textual and historical matters: quite the contrary. In Lukasiewicz's own writing he took pains to back up his interpretations with close textual analysis. That modern scholars have frequently disagreed with his analyses and gone beyond them is a tribute to his method rather than a criticism. What he has banished for good is the thoughtless assumption that because older logicians did not have our modern mathematical tools, or did not follow Aristotle, they were somehow stupid or ignorant.

Lukasiewicz was one of the first logicians - alongside Russell and Leśniewski - to fully understand the genius of Gottlob Frege. The inconsistency of Frege's system notwithstanding, Łukasiewicz was able to appreciate Frege's rigour, clarity and supreme logical craftsmanship, virtues he strove to incorporate into his own work, with considerable success. Philosophically, Łukasiewicz introduced into Poland the anti-psychologistic attitude towards logic that he found in Frege and also in Edmund Husserl. Under his influence, Polish terminology for the bearers of truth-values shifted away from the traditional psychological term sad (judgement) to the more linguistic term zdanie (sentence).

While welcoming the emphasis on rigour and a scientific attitude to philosophy that he found among philosophers of the Vienna Circle, Łukasiewicz was vehemently opposed to their attempts to turn all philosophical problems into linguistic ones, and in particular he was not persuaded that metaphysical discourse is nonsensical. Rather, he persisted in the tradition of Twardowski and Twardowski's teacher Brentano in seeing all philosophical disciplines as aspirationally fully scientific. His own unsurprising take on this was that the best way to ensure such scientificity was to liberally employ mathematical logic in the careful formulation and evaluation of philosophical theses. Not only has Lukasiewicz's reservation about Vienna Circle logical positivism been proved correct: his attitude to the use of logic in philosophy is consonant with that of a significant proportion of philosophers coming after him working in the analytic tradition.

The other highly visible legacy that Lukasiewicz left was the band of exceptionally talented logicians that he helped to train in Poland: not only Alfred Tarski, but also his own doctoral students Mordechaj Wajsberg, Zygmunt Kobrzyński, Stanisław Jaśkowski, Bolesław Sobociński, and Jerzy Słupecki. They continued in his vein of rigorous and independent-minded research long after his death. It was perhaps unfortunate for Lukasiewicz that owing in part to his age he was unable to foster a new generation of talented students abroad, as did many exiled Poles in the United States, the United Kingdom and elsewhere. As it was, his contacts with logicians after 1945 were relatively modest. One was the Irish mathematician Carew Meredith, who became extremely adept under Łukasiewicz's tutelage at finding ever shorter and more elegant single-axiom foundations for logical systems. Of the logicians 
learnt from Łukasiewicz, and Prior's invention of tense logic owed much to Łukasiewicz's inspiration as someone prepared to break logical moulds while keeping an eye on predecessors from the history of logic. Prior was one of the very few logicians of first rank to wholeheartedly adopt Lukasiewicz's logical notation.

Speaking personally, the aspect of Łukasiewicz's approach to logic that I find most congenial is that, notwithstanding his interest in mathematical rigour and technical improvements within logic, his motivations for pursuing heterodox ideas and their maximally rigorous implementation are always philosophical, so that while his background philosophy is always restricted in scope and frequently questionable, it is never absent. He thus fully deserves to be recognized as one of the supreme philosopher-logicians of the twentieth century.

\section{Selected Works by Lukasiewicz}

Collections

Z zagadnień logiki i filozofii. Pisma wybrane. [Topics in Logic and Philosophy. Selected Writings], edited by J. Słupecki (Warsaw: PWN, 1961). [Abbreviated below as $Z$ ].

Selected Works, edited by L. Borkowski (Amsterdam: North-Holland, 1970). [Abbreviated below as $S W$ ].

Logika i Metafizyka. Miscellanea. [Logic and Metaphysics. A Miscellany], edited by J. J. Jadacki (Warsaw: Towarzystwo Naukowe Warszawskie, 1998).

Pamiętnik [Diary], edited by J. J. Jadacki and P. Surma (Warsaw: Semper, 2013) [Contains reminiscences, written mainly around 1949, keyed to certain days of the year, along with miscellaneous recollections by others, assorted biographical and chronological details, and copious photographs].

\section{Monographs}

O zasadzie sprzeczności u Arystotelesa, Studium krytyczne. [On the Principle of Contradiction in Aristotle. A Critical Study.] Kraków: Akademia Umiejętności, 1910. 2nd ed., edited by J. Woleński (Warsaw: PWN, 1987). Translations: Über den Satz vom Widerspruch bei Aristoteles (Hildesheim: Olms, 1993); Del principio di contradizzione in Aristotele (Macerata: Quodlibet, 2003).

Die logischen Grundlagen der Wahrscheinlichkeitsrechnung (Kraków: Spółka Wydawnicza Polska, 1913). Translation: Logical Foundations of Probability Theory, in $S W, 16-63$.

Elementy logiki matematycznej. Skrypt autoryzowany, edited by M. Presburger (Warsaw: Wydawnictwo Koła Matematyczno-Fizycznego Słuchaczów Uniwersytetu Warszawskiego, 1929). 2nd edition, edited by J. Słupecki (Warsaw: PWN, 1958). Translation: Elements of Mathematical Logic (Oxford: Pergamon Press, 1966). Clarendon Press, 1951; 2nd, enlarged edition, 1957). 
Über den Satz von Widerspruch bei Aristoteles. Bulletin internationale de l'Académie des Sciences de Cracovie, Classe de Philosophie (1910), pp. 15-38. Translation: On the principle of contradiction in Aristotle. Review of Metaphysics, 24(1970/71), pp. 485-509; Aristotle on the law of contradiction. In: J. Barnes, M. Schofield and R. Sorabji (eds), Articles on Aristotle 3. Metaphysics (London: Duckworth, 1979), pp. 50-62.

Treść wykładu pożegnalnego wygłoszonego w auli Uniwersytetu Warszawskiego 7 marca 1918 r. Pro arte et studio 3(1918), pp. 3-4. Translation: Farewell lecture delivered in the Warsaw University Lecture Hall on March 7, 1918, in $S W$, pp. 84-86.

O pojęciu możliwości, Ruch Filozoficzne, 5(1920), pp. 169-170. Translation: On the concept of possibility, in $P L$, pp. 15-16.

O logice trójwartościowej, Ruch Filozoficzne, 5(1920), pp. 170-171. Translation: On three-valued logic, in $P L$, pp. 16-18, and in $S W$, pp. 87-88.

Interpretacja liczbowa teorii zdań, Ruch Filozoficzne, 7(1922/23), pp. 92-93. Translation: A numerical interpretation of the theory of propositions, in $S W$, pp. 129-130.

(with A. Tarski) Untersuchungen über den Aussagenkalkül, Comptes rendus de la Société des Sciences et des Lettres de Varsovie, cl. iii, 23 (1930), 1-21. Translation: Investigations into the Sentential Calculus, in $S W$, pp. 131-152.

Philosophische Bemerkungen zu mehrwertigen Systemen des Aussagenkalküls, Comptes rendus de la Société des Sciences et des Lettres de Varsovie, cl. iii, 23 (1930), pp. 51-77. Translation: Philosophical remarks on many-valued systems of propositional logic. In: S. McCall (ed.), Polish Logic, 1920-1939. [Abbreviated below as PL.] (Oxford: Clarendon, 1967), pp. 40-65, and in $S W$, pp. 153-78.

Geneza logiki trójwartościowej [The origins of three-valued logic]. Nauka Polska, 24(1939), pp. 215-223.

A system of modal logic, The Journal of Computing Systems, 1(1953), pp. 111-149, reprinted in $S W$, pp. 352-390.

Arithmetic and modal logic, The Journal of Computing Systems, 1(1954), pp. 213-219, reprinted in $S W$, pp. 391-400.

On a controversial problem of Aristotle's modal syllogistic, Dominican Studies, 7(1954), pp. 114-128.

O determinizmie, in $Z$, pp. 114-126. Translation: On determinism, in $P L$, pp. 19-39, and in $S W$, pp. $110-128$.

\section{About the Author}

Peter Simons holds the Chair of Moral Philosophy (1837) at Trinity College Dublin. 